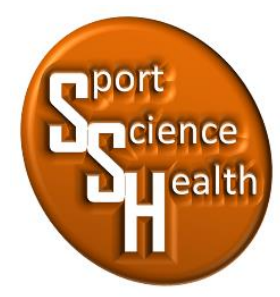

ISSN 2715-3886

\title{
Survei Motivasi Peserta Didik dalam Mengikuti Kegiatan Ekstrakurikuler Futsal
}

\author{
Rizal Dwi Aswanto1* \\ ${ }^{1} J u r u s a n$ Pendidikan Jasmani, Kesehatan dan Rekreasi, Fakultas IImu Keolahragaan, \\ Universitas Negeri Malang, Jalan Semarang No 5, Malang, Jawa Timur, 65145, Indonesia \\ ${ }^{*}$ Penulis koresponden: rizaldwiaswanto97@gmail.com, 087735901616
}

Artikel diterima: 8 Januari 2020; direvisi: 23 Januari 2021; disetujui: 26 Januari 2021

\begin{abstract}
The research design used was survey research with quantitative descriptive research. The research subjects were 100 futsal extracurricular participants in public high schools in Kediri City District. The instrumentused was a Likert scale questionnaire. The data analys is used was the percentage technique. From the results of thedata analysis, 3 conclusions were obtained, namely: (1) Intrinsic motivation, namely 66 students, $66 \%$ were in good category (2) $50 \%$ extrinsic motivation of students is in the sufficient category. (3) The overall motivation, namely 70 students, was in the good category.
\end{abstract}

Keyword: motivation, futsal, extracurricular activities

\begin{abstract}
Abstrak: Rancangan penelitian ini yang digunakan adalah penelitian survei dengan jenis penelitian disktriptif kuantitatif. Subjek pelitian ini sebanyak 100 orang peserta ekstrakurikuler futsal di SMANegeri se-Kecamatan Kota kediri. Instrumen yang digunakan yaitu angket skala likert. Analisis data yang digunakan adalah teknik persentase, dari hasil analisis data diperoleh 3 kesimpulan yaitu:(1) Motivasi intrinsik yaitu 66 pes erta didik $66 \%$ masukkategori baik. (2) Motivasi ekstrinsik 50 peserta didik 50\% masuk kategori cukup. (3) Motivasi keseluruhan yaitu 70 peserta didik $70 \%$ masuk kategori baik.
\end{abstract}

Kata kunci: motivasi, futsal, ekstrakurikuler

\section{PENDAHULUAN}

Olahraga merupakan bagian dari aktivitas sehari-hari manusia yang berguna untuk membentuk jasmani dan rohani yang sehat. Sebagian negara olahraga dijadikan salah satu pembuktian dalam rangka untuk mencapai kejayaan negara. Sejauh ini olahraga telah memberikan peranan yang positif dan nyata bagi peningkatan kesehatan masyarakat. Ada berbagai macam olahraga prestasi yang berkembang saat ini mulai dari olahraga yang bersifat perorangan maupun olahraga berkelompok. Pada masa sekarang olahraga sangat digemari oleh masyarakat umum mulai anak kecil sampai orang dewasa. Tidak sulit untuk melakukan kegiatan olahraga dengan kita berjalan kaki sudah termasuk berolahraga.

Ada banyak macam olahraga salah satunya yaitu futsal. Futsal merupakan olahraga yang sangat disukai oleh masyarakat indonesia, karena dalam memainkan tidak sulit dengan membutuhkan bola saja sudah bisa dimainkan dan tidak membutuhkan lapangan yang luas. Pola permainan dalam futsal banyak didominasi permainan kaki ke kaki, saat bertahan maupun menyerang lebih banyak dilakukan dengan umpan-umpan 
pendek, mengingat ukuran lapangannya lebih kecil dengan lapangan sepak bola (Instituto Brasileiro de Pesquisa e Ensino em Fisiologia do Exercício et al., 2017; Moore, Bullough, Goldsmith, \& Edmondson, 2014; Naser, Ali, \& Macadam, 2017). Permainan futsal sendiri dituntut untuk bermain cepat dari kaki ke kaki saat melakukan serangan ke gawang lawan maupun bertahan. Futsal adalah salah satu cabang olahraga yang dimainkan dua regu, satu regu terdiri dari lima pemain termasuk penjaga gawang. Untuk mencapai tujuan dalam olahraga ini adalah memasukkan bola ke gawang lawan dan mencegah terjadinya gol ke gawang sendiri (Pfirrmann, Herbst, Ingelfinger, Simon, \& Tug, 2016; Unnithan, White, Georgiou, Iga, \& Drust, 2012; Verburgh, Scherder, Van Lange, \& Oosterlaan, 2014). Pada saat itu futsal mulai berkembang pesat dengan ramainya penyewaan lapangan futsal baik dengan memanfaatkan GOR atau membangun gedung khusus futsal (Setyawan, 2010:4).

Pada kehidupan didunia ini tidak dapat memenuhi kebutuhannya tanpa bantuan orang lain, baik kebutuhan biologis maupun kebutuhan ekonomis. Motivasi didenifisikan sebagai dorongan yang berasal dari luar atau dalam individu untuk melakukan suatu aktivitas yang menjamin aktivitas tersebut serta dapat menentukan arah haluan dan besaran upaya yang dikerahkan untuk aktivitas sehingga dapat mencapai tujuan yang ditetapkan (Buckley \& Doyle, 2016; Markus \& Kitayama, 2014; Pelletier et al., 2016). Dengan begitu siswa akan semakin semangat dalam melakukan kegiatan. Motivasi adalah daya pedorong yang mengakibatkan seseorang anggota organisasi mau dan rela untuk mengerahkan kemampuan dalam bentuk keterampilan atau keahlian tenaga untuk melaksanakan berbagai kegiatan yang menjadi tanggung jawabnya dalam memenuhi kewajibannya (Andjarwati, 2015; Nurhidayah, 2015; Suprihatin, 2015). Di sekolah sering terdapat siswa yang malas, tidak menyenangkan, bolos pelajaran, dan sebagainya. Dengan demikian bahwa guru tidak berhasil memberikan motivasi yang tepat kedalam diri anak untuk mendorong agar siswa belajar dengan segenap tenaga dan pikirannya. Dalam hubungan ini seorang siswa mempunyai nilai buruk pada suatu mata pelajaran belum tentu anak itu bodoh terhadap pelajaran tersebut. Mungkin saja anak itu kurangnnya motivasi yang tepat. Banyak bakat anak tidak berkembang disebabkan karena kurangnya motivasi yang tepat dalam diri anak. Jika seorang mendapat motivasi yang tepat, maka timbul rasa untuk menjadi lebih baik dari sebelumnya sehingga tercapai hasil-hasil yang semula tidak terduga. Selain itu untuk soal belajar, motivasi sangat penting karena termasuk salah satu syarat belajar. Pada umumnya tujuan motivasi adalah untuk menggerakkan atau menggugah seorang agar timbul kemauan dan keinginannya untuk melakukan suatu sehingga dapat memperoleh hasil atau mecapai tujuan tertentu (Mayer, 2014; Pintrich, 2013). Dalam pengukuran motivasi instrumen yang digunakan berupa angket. Angket merupakan metode yang menggunakan pertanyaan tertulis untuk memperoleh informasi pribadi terkait responden (Fletcher, 2015; Laing, 2015; Schulz, 2013).

Ekstrakurikuler dalam pendidikan jasmani sangat penting untuk menyalurkan bakat dan pembentukan prestasi siswa. Supaya siswa serius dalam mengikuti ekstrakurikuler tersebut, maka siswa akan dibina dan diarahkan pelatih guna mencapai prestasi yang maksimal dan terarah secara sistematik. Ekstrakurikuler mempunyai arti kegiatan tambahan di luar rencana pembelajaran atau pendidikan tambahan di luar kurikulum. Ekstrakurikuler mempunyai arti kegiatan tambahan di luar rencana pembelajaran atau pendidikan tambahan di luar kurikulum. Kegiatan ekstrakurikuler merupakan kegiatan yang dilaksanakan di luar jam mata pelajaran (kurikulum) untuk menumbuhkembangkan potensi yang dimiliki siswa (Litardiansyah \& Hariyanto, 2020; Rohmatunisha, Wahyudi, \& Yudasmara, 2020). Ekstrakurikuler sendiri mempunyai berbagai macam jenis kegiatan yang berhak diikuti dan peserta didik bebas memilih kegiatan ekstrakurikuler yang sesuai dengan bakat masing masing. Jenis kegiatan tersebut meliputi: sepakbola, bolavoli, bolabasket, renang, futsal. Ekstrakurikuler merupakan kegiatan yang dilaksanakan di luar jam pelajaran biasa dan pada waktu libur sekolah yang dilakukan baik di sekolah maupun di luar sekolah (Almalki, Almojali, Alothman, Masuadi, \& Alaqeel, 2017; Annu \& Sunita, 2013; De Meester, Aelterman, Cardon, De Bourdeaudhuij, \& Haerens, 2014; Fredricks, 2012).

Berdasarkan hasil pengamatan awal pada setiap SMA Negeri se-Kecamatan Kota Kediri. Pada setiap sekolah peneliti mendapati masih ada beberapa peserta ekstrakurikuler yang kurang serius dan bercanda saat kegiatan ekstrakurikuler sedang berlangsung. Hal ini dapat dipengaruhi oleh dua faktor, baik yang berasal dalam diri peserta didik (faktor intrinsik) maupun faktor dari luar diri peserta didik (faktor ekstrinsik). Peserta didik yang mempunyai motivasi besar akan menampakkan minat dan kesungguh-sungguhan yang tinggi dalam melakukan tugasnya, serta mempunyai konsentrasi penuh dan ketekunan yang tinggi untuk mencapai prestasi yang maksimal. Sebaliknya jika peserta didik mempunyai motivasi yang rendah akan cenderung menunjukkan sifat acuh tak acuh, cepat bosan, dan, mudah putus asa. 
Sebelum peneliti memberikan kesimpulan dari penelitian yang akan diambil mengenai motivasi peserta didik dalam mengikuti kegiatan ekstrakurikuler futsal di SMA Negeri se-Kecamatan Kota Kediri maka peneliti ingin memaparkan beberapa penelitian yang relevan Hasil penelitian yang telah dilakukan oleh Herdiansyah (2016:62) tingkat motivasi intrinsik siswa mengikuti ekstrakurikuler futsal MTS Wahid Hasyim memiliki kategori baik dengan presentase $81,83 \%$, sedangkan motivasi ekstrinsik memiliki kategori gagal dengan presentase $38,14 \%$. Dian (2014) tingkat motivasi paling banyak dipengaruhi oleh indikator persaingan dan kebugaran jasmani dengan persentase sebesar $89 \%$.

\section{METODE}

Penelitian ini menggunakan jenis penelitian kuantitatif. Variabel yang diteliti berupa motivasi peserta didik mengikuti ekstrakurikuler futsal di SMA Negeri se-Kecamatan Kota Kediri. Untuk kelengkapan data yang diinginkan, peneliti menggunakan kuisioner dan dokumentasi. Setelah data terkumpul kemudian data dipersentase, setiap kolom terdapat empat alternatif jawaban yaitu: sangat setuju, setuju, tidak setuju, sangat tidak setuju. Pemilihan jawaban pada angket ini menggunakan skala Likert. Skala likert memiliki jangka response lebih besar yang dapat memberikan keterangan yang lebih nyata dan jelas tentang pendapat responden dari apa yang dipertanyakan.

\section{HASIL}

Berdasarkan hasil penelitian diperoleh data bahwa tingkat motivasi intrinsik peserta didik dalam mengikuti kegiatan ekstrakurikuler futsal di SMA Negeri se-Kecatamatan dalam aspek minat yaitu 3 peserta didik $3 \%$ masuk kategori cukup, 15 peserta didik 15\% masuk kategori baik, 82 peserta didik $82 \%$ masuk kategori sangat baik. Aspek kepuasan yaitu 4 peserta didik $4 \%$ masuk kategori cukup, 13 peserta didik $13 \%$ masuk kategori baik, 83 peserta didik $83 \%$ masuk kategori sangat baik. Aspek perasaan yaitu 1 peserta didik $1 \%$ masuk kategori cukup, 22 peserta didik 22\% masuk kategori baik, 77 peserta didik $77 \%$ masuk kat egori sangat baik. Aspek bakat yaitu 17 peserta didik 17\% masuk kategori baik, 83 peserta didik $83 \%$ masuk kategori sangat baik. Berdasarkan data peneltian diperoleh data bahwa tingkat motivasi ekstrinsik peserta didik dalam mengikuti kegiatan ekstrakurikuler di SMA Negeri se-Kecamatan dalam aspek lingkungan yaitu 1 peserta didik $1 \%$ masuk kategori kurang, 2 peserta didik $2 \%$ masuk kategori cukup, 44 peserta didik $44 \%$ masuk kategori baik, 53 peserta didik 53\% masuk kategori sangat baik. Aspek penghargaan yaitu 0 peserta didik $0 \%$ masuk kategori sangat kurang, 2 peserta didik $2 \%$ masuk kategori kurang, 8 peserta didik $8 \%$ masuk kategori cukup, 40 peserta didik $40 \%$ masuk kategori baik, 50 peserta didik $50 \%$ masuk kategori sangat baik. Aspek persaingan 1 peserta didik 1\% masuk kategori kurang, 12 peserta didik 12\% masuk kategori cukup, 41 peserta didik $41 \%$ masuk kategori baik, 46 peserta didik $46 \%$ masuk kategori sangat baik.

Berdasarkan hasil penelitian diperoleh data bahwa tingkat motivasi peserta didik dalam mengikuti kegiatan ekstrakurikuler futsal di SMA Negeri se-kecamatan Kota Kediri yaitu 30 peserta didik $30 \%$ masuk kategori cukup, 70 peserta didik $70 \%$ masuk kategori baik.

\section{PEMBAHASAN}

\section{Motivasi Peserta Didik dalam mengikuti Ekstrakurikuler Futsal di SMA Negeri sekecamatan Kota Kediri}

Berdasarkan hasil data penelitian yang didapatkan, motivasi intrinsik dalam aspek minat peserta didik memiliki persentase terbesar $82 \%$ dengan jumlah 82 peserta didik masuk pada kategori sangat baik dan persentase skor keseluruhan dari peserta didik adalah 90,69\%. Hasil ini menjelaskan bahwa peserta didik dalam mengikuti kegiatan ekstrakurikuler futsal banyak yang memiliki motivasi intrinsik aspek minat yang sangat baik. Motivasi intrinsik dalam aspek kepuasan peserta didik memiliki persentase terbesar $83 \%$ dengan jumlah 83 peserta didik masuk pada kategori sangat baik dan persentase skor keseluruhan yang didapat dari peserta didik adalah $89,33 \%$. Hasil ini dapat menjelaskan bahwa lebih banyak peserta didik memiliki motivasi intrinsik aspek kepuasan yang sangat baik dalam mengikuti kegiatan ekstrakurikuler futsal. Motivasi intrinsik dalam aspek perasaan peserta didik memiliki persentase terbesar $77 \%$ dengan jumlah 77 peserta didik masuk pada kategori sangat baik dan persentase skor keseluruhan yang didapat dari peserta didik adalah $90,13 \%$. Hasil 
ini dapat menjelaskan bahwa lebih banyak peserta didik memiliki motivasi intrinsik aspek pengetahuan yang sangat baik dalam mengikuti kegiatan ekstrakurikuler futsal., Motivasi intrinsik peserta didik memiliki persentase terbesar $83 \%$ dengan jumlah 83 peserta didik masuk pada kategori sangat baik dan persentase skor keseluruhan yang didapat dari peserta didik adalah $91,1 \%$. Hasil ini dapat menjelaskan bahwa lebih banyak peserta didik memiliki motivasi intrinsik yang sangat baik dalam kegiatan ekstrakurikuler futsal. Motivasi intrinsik merupakan motivasi yang baik untuk dimiliki peserta didik karena peserta didik yang memiliki motivasi intrinsik tinggi akan lebih mudah dalam melakukan suatu kegiatan yang di inginkannya.

Hasil ini mendukung hasil penelitian yang pernah dilakukan oleh Herdiansyah (2014) bahwa motivasi intrinsik yang dimiliki peserta didik dalam mengikuti kegiatan ekstrakurikuler futsal di MTS Wahid hasyim 02 desa Kucur Kecamatan Dau Kabupaten Malang termasuk kategori baik sekali dengan persentase $84,16 \%$. Jadi dapat disumpulkan peserta didik di SMA Negeri se-Kecamatan Kota Kediri memiliki motivasi intrinsik yang baik dalam mengikuti kegiatan ekstrakurikuler futsal.

Berdasarkan hasil data penelitian yang didapatkan, motivasi ekstrinsik dalam aspek lingkungan peserta didik memiliki persentase terbesar 53\% dengan jumlah 53 peserta didik masuk pada kategori tinggi dan persentase skor keseluruhan yang didapat dari peserta didik adalah 53,65\%. Hasil ini dapat menjelaskan bahwa lebih banyak peserta didik memiliki motivasi ekstrinsik aspek lingkungan yang sangat baik dalam mengikuti kegiatan ekstrakurikuler futsal. Motivasi ekstrinsik dalam aspek persaingan peserta didik memiliki persentase terbesar $46 \%$ dengan jumlah 46 peserta didik masuk pada kategori tinggi dan persentase skor keseluruhan yang didapat dari peserta didik adalah $83,1 \%$. Hasil ini dapat menjelaskan bahwa lebih banyak peserta didik memiliki motivasi ekstrinsik aspek persaingan yang sangat baik dalam mengikuti kegiatan ekstrakurikuler futsal. Motivasi ekstrinsik dalam aspek penghargaan peserta didik memiliki persentase terbesar $50 \%$ dengan jumlah 50 peserta didik masuk pada kategori tinggi dan persentase skor keseluruhan yang didapat dari peserta didik adalah $82,1 \%$. Hasil ini dapat menjelaskan bahwa lebih banyak peserta didik memiliki motivasi ekstrinsik aspek penghargaan yang sangat baik dalam mengikuti kegiatan ekstrakurikuler futsal se-Kecamatan Kota Kediri

Hasil ini mendukung hasil penelitian yang pernah dilakukan oleh Herdiansyah (2014) bahwa motivasi ekstrinsik yang dimiliki peserta didik dalam mengikuti kegiatan ekstrakurikuler futsal di MTS Wahid hasyim 02 desa Kucur Kecamatan Dau Kabupaten Malang termasuk kategori kurang dengan persntase 38,14\%. Jadi dapat disumpulkan peserta didik di SMA Negeri se-Kecamatan Kota Kediri memiliki motivasi ekstrinsik yang cukup dalam mengikuti kegiatan ekstrakurikuler futsal.

Berdasarkan hasil data penelitian yang didapatkan, motivasi peserta didik memiliki persentase terbesar $70 \%$ dengan jumlah 70 peserta didik masuk pada kategori baik dan persentase skor keseluruhan yang didapat dari peserta didik adalah $86,73 \%$. Hasil ini dapat menjelaskan bahwa lebih banyak peserta didik memiliki motivasi baik dalam mengikuti kegiatan ekstrakurikuler futsal.

Hasil yang didapatkan penelitian ini mendapatkan perbedaan pada persentase yaitu $70 \%$ dengan kategori baik sedangkan penelitian sebelumnya yang dilakukan Dian Langlang Setanggi (2014) menyatakan bahwa motivasi siswa dalam mengikuti ekstrakurikuler futsal di SMP Citra Berkat Surabaya memiliki persentase 89\% atau termasuk kategori baik. Adapun penelitian yang telah dilakukan oleh Herdiansyah (2014) menyatakan bahwa motivasi peserta didik dalam kategori baik sekali dengan persentase $84,16 \%$.

Jadi dapat diambil kesimpulan bahwa peserta didik termotivasi dalam mengikuti kegiatan ekstrakurikuler futsal dengan kategori baik. Semua motivasi yang dimiliki peserta didik dalam mengikuti kegiatan ekstrakurikuler futsal tergantung bagaimana pelatih mengemas materi latihan agar menarik. Apabila pelatih bisa membuat materi latihan yang sangat menarik pasti pesrta didik akan tertarik dan menumbuhkan motivasinya.

\section{KESIMPULAN}

Berdasarkan hasil penelitian yang telah di dapat maka diperoleh kesimpulan sebagai berikut. (1) Motivasi intrinsik peserta didik dalam mengikuti kegiatan ekstrakurikuler futsal di SMA Negeri se-Kecamatan Kota kediri yaitu 5 pesrta didik 5\% masuk ketegori cukup, 66 peserta didik 66\% masuk kategori baik, 29 peserta didik $29 \%$ masuk kategori sangat baik. Jadi dapat disumpulkan motivasi instrinsik dikategorikan baik. (2) Motivasi ekstrinsik peserta didik dalam mengikuti kegiatan ekstrakurikuler futsal di SMA Negeri se-Kecamatan Kota Kediri yaitu 3 peserta didik 3\% masuk kategori kurang, 50 peserta didik 50\% masuk kategori cukup, 47 peserta 
didik 47\% masuk kategori baik. Jadi dapat disumpulkan motivasi ekstrinsik dikategorikan cukup. (3) Motivasi peserta didik dalam mengikuti kegiatan ekstrakurikuler futsal di SMA Negeri se-Kecamatan Kota Kediri yaitu 30 peserta didik $30 \%$ masuk kategori cukup, 70 peserta didik $70 \%$ masuk kategori baik. Jadi dapat disimpulkan motivasi yang dimiliki peserta didik dikategorikan baik.

\section{DAFTAR PUSTAKA}

Almalki, S. A., Almojali, A. I., Alothman, A. S., Masuadi, E. M., \& Alaqeel, M. K. (2017). Burnout and its association with extracurricular activities among medical students in Saudi Arabia. International Journal of Medical Education. https://doi.org/10.5116/ijme.58e3.ca8a

Andjarwati, T. (2015). Motivasi dari Sudut Pandang Teori Hirarki Kebutuhan Maslow, Teori Dua Faktor Herzberg, Tero X Y Mc Gregor, dan Teori Motivasi Prestasi Mc Clelland. Jurnal IImu Ekonomi \& Manajemen.

Annu, S., \& Sunita, M. (2013). Impact of Extracurricular Activities on Students. International Journal of Humanities and Social Science Invention.

Buckley, P., \& Doyle, E. (2016). Gamification and student motivation. Interactive Learning Environments. https://doi.org/10.1080/10494820.2014.964263

De Meester, A., Aelterman, N., Cardon, G., De Bourdeaudhuij, I., \& Haerens, L. (2014). Extracurricular schoolbased sports as a motivating vehicle for sports participation in youth: A cross-sectional study. International Journal of Behavioral Nutrition and Physical Activity. https://doi.org/10.1186/1479-5868$11-48$

Fletcher, E. (2015). Interpreting qualitative data. International Journal of Research \& Method in Education. https://doi.org/10.1080/1743727x.2015.1066173

Fredricks, J. A. (2012). Extracurricular Participation and Academic Outcomes: Testing the Over-Scheduling Hypothesis. Journal of Youth and Adolescence. https://doi.org/10.1007/s10964-011-9704-0

Instituto Brasileiro de Pesquisa e Ensino em Fisiologia do Exercício, R., Cardoso, M. F. da S., Cicero Moraes, J., Cunha, G. dos S., Eloi Gomes Voser, P., \& Morais, M. L. (2017). Revista brasileira de futsal e futebol. RBFF - Revista Brasileira de Futsal e Futebol, ISSN-e 1984-4956, Vol. 9, No. 34, 2017, Págs. 258-264.

Langlang. S. 2014. Motivasi Siswa Dalam Mengikuti Ekstrakurikuler Futsal Di SMP Citra Berkat Surabaya. Jurnal Pendidikan Olahraga dan Kesehatan 2(3), 844 - 84

Laing, K. (2015). Constructing research questions: doing interesting research. International Journal of Research \& Method in Education, 38(2), 219-220. https://doi.org/10.1080/1743727x.2015.1005803

Litardiansyah, B. A., \& Hariyanto, E. (2020). Survei Kondisi Fisik Peserta Ekstrakurikuler Futsal Putra dan Putri Sekolah Menengah Atas. Sport Science and Health, 2(6), 331-339. Retrieved from http://journal2.um.ac.id/index.php/jik/article/view/14090/5925

Markus, H. R., \& Kitayama, S. (2014). Culture and the self: Implications for cognition, emotion, and motivation. In College Student Development and Academic Life: Psychological, Intellectual, Social and Moral Issues. https://doi.org/10.1037//0033-295x.98.2.224

Mayer, R. E. (2014). Incorporating motivation into multimedia learning. Learning and Instruction. https://doi.org/10.1016/j.learninstruc.2013.04.003

Moore, R., Bullough, S., Goldsmith, S., \& Edmondson, L. (2014). A Systematic Review of Futsal Literature. American Journal of Sports Science and Medicine. https://doi.org/10.12691/ajssm-2-3-8

Naser, N., Ali, A., \& Macadam, P. (2017). Physical and physiological demands of futsal. Journal of Exercise Science and Fitness. https://doi.org/10.1016/j.jesf.2017.09.001

Nurhidayah, D. A. (2015). Pengaruh Motivasi Berprestasi dan Gaya Belajar Terhadap Prestasi Belajar Siswa Pada Mata Pelajaran Matematika SMP. Jurnal Dimensi Pendidikan Dan Pembelajaran. https://doi.org/http://dx.doi.org/10.24269/dpp.v3i2.83 
Pelletier, L. G., Tuson, K. M., Fortier, M. S., Vallerand, R. J., Briére, N. M., \& Blais, M. R. (2016). Toward a New Measure of Intrinsic Motivation, Extrinsic Motivation, and Amotivation in Sports: The Sport Motivation Scale (SMS). Journal of Sport and Exercise Psychology. https://doi.org/10.1123/jsep.17.1.35

Pfirrmann, D., Herbst, M., Ingelfinger, P., Simon, P., \& Tug, S. (2016). Analysis of injury incidences in male professional adult and elite youth soccer players: A systematic review. Journal of Athletic Training. https://doi.org/10.4085/1062-6050-51.6.03

Pintrich, P. R. (2013). Educational psychologist. In Educational Psychologist. https://doi.org/10.4324/9781315046372

Rohmatunisha, S., Wahyudi, U., \& Yudasmara, D. S. (2020). Survei Minat Siswa dalam Mengikuti Kegiatan Ekstrakurikuler Bolabasket pada Peserta Sekolah Menengah Pertama. Sport Science and Health, 2(2), 119-129. Retrieved from http://journal2.um.ac.id/index.php/fik/article/view/11266/5286

Schulz, J. (2013). Research methods in educational leadership and management. International Journal of Research \& Method in Education. https://doi.org/10.1080/1743727x.2012.752206

Suprihatin, S. (2015). UPAYA GURU DALAM MENINGKATKAN MOTIVASI BELAJAR SISWA. PROMOSI (Jurnal Pendidikan Ekonomi). https://doi.org/10.24127/ja.ßBi1.144

Unnithan, V., White, J., Georgiou, A., Iga, J., \& Drust, B. (2012). Talent identification in youth soccer. Journal of Sports Sciences. https://doi.org/10.1080/02640414.2012.731515

Verburgh, L., Scherder, E. J. A., Van Lange, P. A. M., \& Oosterlaan, J. (2014). Executive functioning in highly talented soccer players. PLOS ONE. https://doi.org/10.1371/journal.pone.0091254 